\title{
An Objective Frontal Data Set to Represent the Seasonal and Interannual Variations in the Frontal Zone around Japan
}

\author{
Nobuto TAKAHASHI \\ School of Food, Agricultural and Environmental Sciences Miyagi University, Sendai, Japan
}

(Manuscript received 16 April 2012, in final form 28 February 2013)

\begin{abstract}
A long-term (1948-2009) frontal data set was created with an objective method by using NCEP-NCAR (National Centers for Environmental Prediction-National Center for Atmospheric Research) reanalysis data. This method utilizes a gradient and a thermal front parameter (TFP) of a potential temperature and an equivalent potential temperature at $850 \mathrm{hPa}(d \theta, \operatorname{TFP}(\theta)$, and $\operatorname{TFP}(\theta e))$. The TFP defined as the directional derivative of a gradient of a thermodynamic variable along its gradient is one of the measures of frontal intensity and is often used for objectively analyzing frontal positions on surface weather maps. On the basis of the frontal data set, the average seasonal behavior of the frontal zone around Japan, its influence on the weather in mid-summer, and the seasonal march of the frontal zone during El Niño/La Niña events were examined. The main results are summarized in the following points: 1) The frontal data set generated under the conditions of $d \theta>0.04 \mathrm{~K}(100 \mathrm{~km})^{-1}, \operatorname{TFP}(\theta)>0.05 \mathrm{~K}(100 \mathrm{~km})^{-2}$, and $\operatorname{TFP}(\theta e)>$ $0.69 \mathrm{~K}(100 \mathrm{~km})^{-2}$ showed the strongest correlation to that compiled by counting the number of fronts on the surface weather maps around Japan. 2) Although the long-term frontal data set created in this study retained some differences in frequency, the seasonal march of the frontal zone was consistent with that created from fronts on the weather maps. 3) The relationship of interannual mid-summer variations (July 20-August 16) between the clear-sky ratio of Japan and the frontal zone and various mean characteristics of the Japanese climate during El Niño/La Niña events, most of which have been discussed in previous reports, were verified from the perspective of the variability in the frontal zone, which has not been clarified so far.

These results of this work show that the frontal data set created herein has the advantage of being simple and objective and is useful for research on the detailed relationship in interannual variations between the regional climate around Japan and large-scale atmospheric conditions.
\end{abstract}

Keywords frontal zone; Japan climate system; clear-sky ratio in mid-summer; El Niño/La Niña events

\section{Introduction}

Atmospheric fronts on daily weather maps are expressions of one aspect of the atmospheric conditions and are therefore analyzed to understand the local weather and the state of the air. A location where fronts frequently appear within a certain period is termed a frontal zone in climatology (Yoshimura 1985). A frontal zone expresses one aspect of the averaged

Corresponding author: Nobuto Takahashi, School of Food, Agricultural and Environmental Sciences, Miyagi University, 2-2-1, Hatatate, Taihaku-ku, Sendai 982-0215, Japan.

E-mail: nobuto@myu.ac.jp

(C)2013, Meteorological Society of Japan atmospheric circulation pattern and is strongly correlated with the neighboring climate. From another perspective, frontal zone data can describe in detail the relations between the regional climate and the atmospheric circulation. Therefore, an understanding of seasonal and interannual behaviors of frontal zones is important for understanding climate systems. However, the seasonal and interannual behaviors remain largely unknown for most frontal zones owing to the lack of long-term frontal zone data. In this work, a new methodology for calculating frontal zone data around Japan is submitted, and the seasonal and interannual behaviors of frontal zones are clarified using the frontal data set. 
Most previous works concerned with frontal zones have focused on the relationships between the frontal zone and regional climate, as noted by Yazawa (1989). For instance, Bergeron (1930) showed the relationships between front distribution and the air masses, wind, and precipitation in various regions over the Pacific Ocean in summer and winter. Alissow (1954) submitted the famous climatic classification on the basis of the seasonal march of the locations of frontal zones and air masses on a global scale.

Over and around Japan, the Baiu front and the Akisame front, which frequently appear on surface weather maps and which cause rainfall over all of Japan from June to July and from September to October, respectively, have been previously investigated by many researchers. For instance, the mean relationships on the seasonal march between the frontal zone and rainfall distributions in the Baiu season and Akisame season were examined by Yoshino (1965) and Takahashi (2003), respectively. These former works proved that the frontal zone has a strong relationship with the regional climate. The mean behavior of the frontal zone itself was also investigated, as Yoshimura (1967) delineated the seasonal distribution of the frontal frequencies in the Northern Hemisphere, and Takahashi (2009; hereafter T2009) calculated the mean seasonal march of the distributions of the frontal frequencies around Japan on an every-five-day basis from April to November over 29 years from 1979 to 2007 . All these previous works were performed using frontal data sets created by counting fronts on daily weather maps.

Few prior studies have tried to investigate longterm behavior of frontal zones, even though it is important for understanding regional climate changes. There are two primary reasons for this: one reason is the difficulty in creating a long-term frontal data set from daily surface weather maps, which is a laborious process. The second reason is that the homogeneity of a long-term frontal data set made from daily surface weather maps is less than desirable, because the fronts are subjectively drawn by the analyzer.

The methods of objectively drawing fronts on daily surface weather maps have been previously developed by several researchers, e.g., Renard and Clarke (1965), Japan Meteorological Agency (JMA) (1988), Hewson (1998), and Tomita et al. (2011). Renard and Clarke (1965) suggested using the thermal front parameters $(T F P)$ defined as follows:

$$
\operatorname{TFP}(\tau)=-\frac{\nabla|\nabla \tau| \cdot \nabla \tau}{|\nabla \tau|}
$$

Here $\tau$ is a thermodynamic variable, e.g., $\theta$ (potential temperature), or $\theta w$ (wet-bulb potential temperature). The $\operatorname{TFP}(\tau)$ defined as the directional derivative of a gradient of $\tau$ along its gradient is one of the measures of frontal intensity and is often used for objectively analyzing the frontal positions on surface weather maps. The JMA calculates the TFP using 500-1000 $\mathrm{hPa}$ layer thickness as $\tau$, and drafts and refers to the lines showing the maxima of the TFP, called NP fronts, before manually drawing the fronts (JMA 1988). Hewson (1998) examined various methods to determine the existence or nonexistence of fronts on daily weather maps using the $\operatorname{TFP}(\tau)$, the gradient of $\tau$, and other parameters. Hewson's (1998) preferred method of drawing fronts was applied by Serreze et al. (2001), who documented the seasonal changes in Arctic fronts in the Northern Hemisphere. Note that the thermal parameter and other conditions must be chosen in advance in order to obtain the objective fronts corresponding to the fronts drawn on the weather maps, as discussed in further detail in Section 2.

The purpose of this work is to create a long-term frontal data set corresponding to the locations and frequencies of fronts around Japan, as shown on daily weather maps. This required testing a few thermal parameters and various conditions to find the best fit. Further, the seasonal and interannual behaviors and the influence of the frontal zone on the weather in Japan were examined using the frontal data set. In particular, this study examined the seasonal marches of the frontal zone around Japan during El Niño/La Niña events and the relationships between the frontal zone and the clear-sky ratio in Japan during mid-summer (July 20August 18). Mid-summer was chosen because the interannual variations in activities and the northernmost points of the frontal zone are large and they strongly influence the climate of Japan during this period. The data and methodology for the creation of the objective frontal data set are detailed in Section 2. The characteristics of the resultant objective frontal data set around Japan are compared with the fronts on the weather maps in Section 3. The relationships between the frontal zone and the clear-sky ratio in Japan during mid-summer are shown in Section 4. Finally, the averaged seasonal marches of frontal zone around Japan associated with the occurrence of El Niño/La Niña events are discussed in Section 5.

\section{Creation and evaluation of the frontal data set}

\subsection{Data and methodology}

The objective frontal analysis scheme proposed by Hewson (1998), which utilizes the grid data of 
atmospheric parameters, was used to generate an atmospheric frontal data set around Japan. In this scheme, the grids where the gradient of $\operatorname{TFP}(\tau)$ equals zero, called "a potential front," are identified (see the definition of $\operatorname{TFP}(\tau)$ in Section 1). The grids where a potential front exists are additionally examined by the two masking variables - a gradient and a thermal front parameter of $\tau$. If both variables exceed the respective prescribed threshold, a front is considered to exist on that grid. The gradients used in the calculations were estimated by the technique described by Horn (1981), which uses the values of neighbor $3 \times 3$ grids, including the examined grid in the center. In the process of these calculations, the thermodynamic variables to be used and the thresholds of a gradient of $\tau$ and $\operatorname{TFP}(\tau)$ must be decided in advance. As for the thermodynamic variable $\tau$, Hewson (1998) showed that $\theta$ or $\theta w$ in the lower atmosphere is compatible with the result of manual frontal analysis, but has a principal disadvantage of "Foehn effect fronts," commonly observed when using $\theta$ and of "warm conveyor belt fronts," commonly observed when using $\theta w$. Furthermore, this previous work suggested that these disadvantages could be removed when using the intersection of $\theta$ fronts and $\theta w$ fronts, and recommended the use of thermodynamic variables at $900 \mathrm{hPa}$, which is considered as the level for representing surface fronts. On the other hand, in daily frontal analysis for the surface weather map in Japan, $\theta e$ (equivalent potential temperature) at $850 \mathrm{hPa}$ is commonly utilized to monitor the water vapor field, which is closely associated with the frontal activity around Japan. Moreover, the differences between the thermodynamic variables of $\theta w$ and $\theta e$ and those between the levels $850 \mathrm{hPa}$ and $900 \mathrm{hPa}$ result in almost no change in frontal analysis. Therefore, $\theta$ and $\theta e$ at $850 \mathrm{hPa}$ were utilized as the thermodynamic variable $\tau$.

$\theta$ and $\theta e$ at $850 \mathrm{hPa}$ were calculated by using temperature and relative humidity data for the range $15^{\circ}-60^{\circ} \mathrm{N}, 110^{\circ}-160^{\circ} \mathrm{E}$, which includes the Japanese Archipelago, for a period of 62 years from 1948 to 2009; the data were obtained from the National Centers for Environmental Prediction-National Center for Atmospheric Research (NCEP-NCAR) reanalysis (Kalnay et al. 1996). The NCEP-NCAR reanalysis data are six-hourly products archived on regular $2.5^{\circ}$ latitude-longitude grids. Although these data are known to include some errors, e.g., spectral distortion at high latitudes in the moisture field, as reported by Serreze and Hurst (2000), the influence of these errors on this work is small because the study area in this work comprises the mid-latitude region. These reanalysis data have the advantage that a longer period (more than 60 years) can be analyzed than that which is possible using many other reanalysis data, e.g., ERA40 (ECMWF 40-year reanalysis project), or JRA-25 (Japanese 25-year reanalysis project). Each value of $\theta$ and $\theta e$ at $850 \mathrm{hPa}$ is estimated by using the formula submitted by Bolton (1980).

The conditions of $d \theta, \operatorname{TFP}(\theta), d \theta e$, and $\operatorname{TFP}(\theta e)$ required to examine the existence or nonexistence of a front are determined by comparison with the frontal data set used in T2009 (the T2009 data set), for each grid. The T2009 data set was compiled by counting fronts on the surface weather maps published by the JMA. The time-spatial ranges and resolutions are twice-daily and $10^{\circ}$ longitude by $1^{\circ}$ latitude global grids around Japan $\left(15^{\circ}-60^{\circ} \mathrm{N}, 110^{\circ}-160^{\circ} \mathrm{E}\right)$, respectively, for a period of 29 years from 1979 to 2007 . Note that this T2009 data set is limited to the summer monsoon season from April to November when the frontal zone is located around the Japanese Archipelago.

A specific three-step procedure for making one frontal data set in agreement with the T2009 data set is presented here.

1) By changing the thresholds of $d \theta$ from 0.01 to $0.40(100 \mathrm{~km})^{-1}$ with $0.01(100 \mathrm{~km})^{-1}$ intervals, and $\operatorname{TFP}(\theta)$ from 0.01 to $0.20 \mathrm{~K}(100 \mathrm{~km})^{-2}$ with $0.01 \mathrm{~K}(100 \mathrm{~km})^{-2}$ intervals including null values, $800(40 \times 20)$ data sets of $\theta$ fronts are calculated. Similarly, 4,000 $(100 \times 40)$ data sets of $\theta e$ fronts are made by changing the thresholds of $d \theta e$ from 0.01 to $0.40 \mathrm{~K}(100 \mathrm{~km})^{-1}$ with 0.01 $\mathrm{K}(100 \mathrm{~km})^{-1}$ intervals, and from 0.01 to $1.00 \mathrm{~K}$ $(100 \mathrm{~km})^{-2}$ with $0.01 \mathrm{~K}(100 \mathrm{~km})^{-2}$ intervals including null values.

2) Every frontal data set $(X)$ is evaluated by comparison with the T2009 data set (Y) using the Jaccard similarity index $(J I)$. The $J I$ is calculated between two data sets as follows:

$$
J I(X, Y)=\frac{|\boldsymbol{X} \cap \boldsymbol{Y}|}{|\boldsymbol{X} \cup \boldsymbol{Y}|}
$$

The $J I$ ranges between 0 and 1 , and the greater the similarity between the two data sets, the closer to 1 the value of the $J I$ approaches. In this calculation, two data sets are considered to be cooccurring when a gap of frontal position between two fronts is $5^{\circ}$ or less in latitude. Here, $5^{\circ}$ of latitude was chosen, in part because the positions of two frontal data sets often have a large gap, especially in the case of a front that stretches north to south over a large distance despite having 
a comparatively small east-west extent, and in part because there is also a difference in the spatial resolutions of the two data sets.

3) The thresholds of $d \tau$ and $\operatorname{TFP}(\tau)$ are found when the maximum $J I(M J I)$ appears in the comparison. Figure 1 is an example of the determination of the thresholds of $d \tau(\mathrm{x}$-axis) and $\operatorname{TFP}(\tau)(\mathrm{y}-$ axis) when $\theta$ is utilized as the thermodynamic variable $\tau$. The region and period for calculations are $25^{\circ}-35^{\circ} \mathrm{N}$ at $140^{\circ} \mathrm{E}$ and April-November, respectively. In this example, the value of $M J I$ is found to be 0.461 when using the following conditions: $d \tau>0.28 \mathrm{~K}(100 \mathrm{~km})^{-1}$ and $\operatorname{TFP}(\tau)>$ $0.08 \mathrm{~K}(100 \mathrm{~km})^{-2}$. Thus, this figure shows that these thresholds can help realize a frontal data set most similar to the T2009 data set.

However, because the $M J I$ and suitable thresholds may change within the range of areas and periods in calculation, the specific region and period for making frontal data set are determined on the basis of the regional and temporal features of MJIs when using the data sets of $\theta$ or $\theta e$ fronts in Section 2.2. Then, the intersections of $\theta$ and $\theta e$ fronts, ( $\theta$ fronts $) \cap(\theta e$ fronts $)$, are shown in the region and period, in which the thresholds of four parameters; $\theta, \theta e, \operatorname{TFP}(\theta)$, and $\operatorname{TFP}(\theta e)$ were changed, and 3,200,000 $(800 \times 4,000)$ data sets were accordingly prepared. In the process of calculation, a gap with 1 or 2 grids $\left(2.5^{\circ}\right.$ or $5^{\circ}$ latitude) between $\theta$ and $\theta e$ fronts required the following adjustment: the frontal position was placed on the grid where the $\theta e$ front was located (between the $\theta$ and $\theta e$ fronts) when a gap was 1 grid ( 2 grids), because the positions of $\theta e$ fronts were usually more in agreement with the fronts on the weather map than those of $\theta$ fronts in most regions, as shown by Hewson (1998). After the evaluation of every frontal data set by $J I$, the thresholds of $\theta, \theta e, \operatorname{TFP}(\theta)$, and $\operatorname{TFP}(\theta e)$ were examined in the case when the $M J I$ appears and one frontal data set was chosen to be used in this work.

\subsection{Evaluation of frontal data sets}

The regional and temporal compatibility between the T2009 data set and every frontal data set created as discussed in Section 2.1 was evaluated with the values of MJIs. The period for calculation of MJIs was set to that of T2009, i.e., twice daily from April to November for 29 years from 1979 to 2007. Figure 2 shows the distribution maps of MJIs calculated using the data sets of $\theta$ (Fig. 2a) or $\theta e$ (Fig. 2b) fronts. The values in each grid cell of $5^{\circ}$ longitude by $5^{\circ}$ latitude indicates $M J I$ (unit: $\times 0.01$ ), which is calculated over a latitudinal width of $10^{\circ}$ along longitudinal intervals of $5^{\circ}$. Each

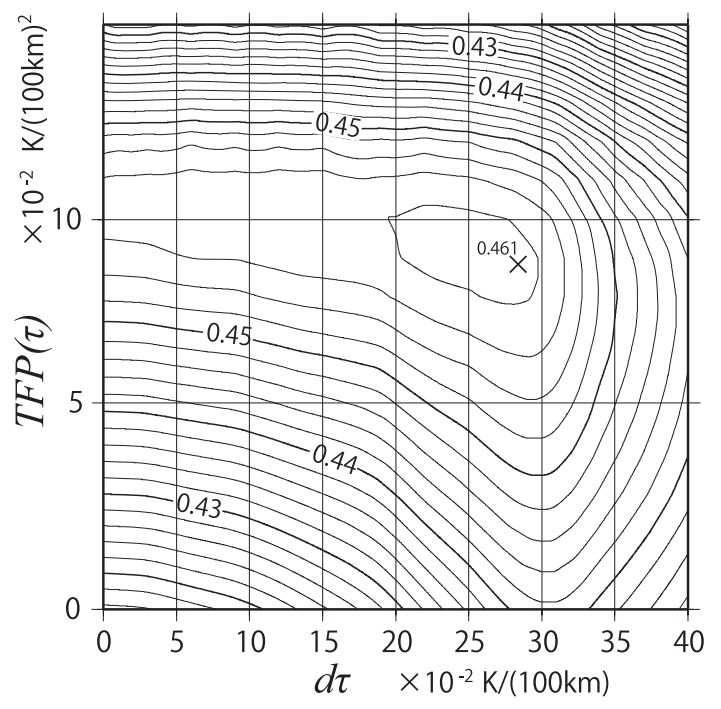

Fig. 1. An example of the $d \tau-T F P(\tau)$ section of the Jaccard Index $(J I)$. In this example, $\theta$ is utilized as the thermodynamic variable $\tau$, and the region and period for calculations are $25^{\circ}-35^{\circ} \mathrm{N}$ at $140^{\circ} \mathrm{E}$ and April-November, respectively. The units of $d \tau$ and $\operatorname{TFP}(\tau)$ are $10^{-2} \mathrm{~K}(100$ $\mathrm{km})^{-1}$ and $10^{-2} \mathrm{~K}(100 \mathrm{~km})^{-2}$, respectively.

$M J I$ value was computed using different pairs of conditions of $d \tau$ and $\operatorname{TFP}(\tau)$ (data not shown). In both Figs. $2 \mathrm{a}$ and $2 \mathrm{~b}$, the high MJIs (more than +0.300 , shown in shaded area) are spread around Japan, but most of the lower MJIs occur south of $20^{\circ} \mathrm{N}$ and north of $45^{\circ} \mathrm{N}$. The difference between the characteristics of $\theta$ and $\theta e$ fronts is also seen in that the MJIs of the $\theta e$ fronts exhibit higher values than those of the $\theta$ fronts in most regions around Japan. This characteristic is in agreement with the work of Hewson (1998), which shows that $\theta w$ fronts ( $\theta e$ fronts used in this work) are more congruent with daily frontal analyses than are $\theta$ fronts. Considering the $M J I$ distributions and that each $M J I$ was calculated using fronts in the range of $10^{\circ}$ width in latitude, the range of $120^{\circ}-160^{\circ} \mathrm{E}, 25^{\circ}-40^{\circ} \mathrm{N}$ around Japan was chosen as the region for creating one frontal data set.

Table 1 lists the monthly $M J I$ and its thresholds when using the T2009 data set and $\theta$ (Table 1a) or $\theta e$ (Table 1b) fronts, which were calculated in the region of $120^{\circ}-160^{\circ} \mathrm{E}, 25^{\circ}-40^{\circ} \mathrm{N}$. The bottom rows of Tables $1 \mathrm{a}$ and $1 \mathrm{~b}$ indicate the $M J I s$ for the periods from April to November. In both Tables $1 \mathrm{a}$ and $1 \mathrm{~b}$, the MJIs have low values in April, August, and November when fronts are farther from the Japanese Archipelago, as can be inferred from the spatial features of MJIs in Fig. 
a) $\theta$ fronts

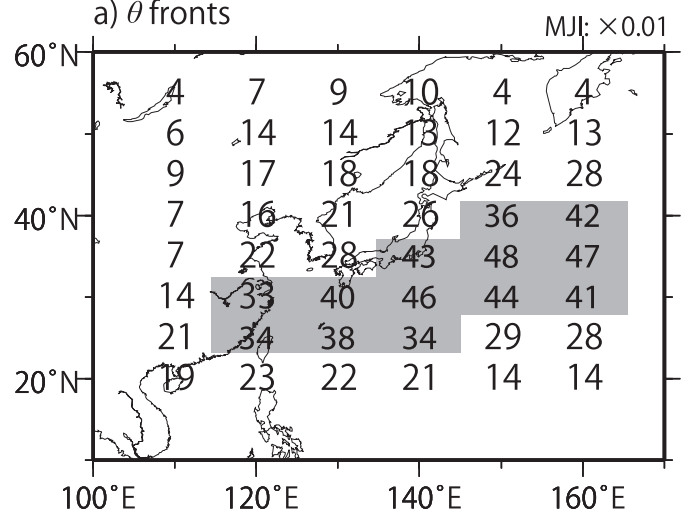

b) $\theta e$ fronts

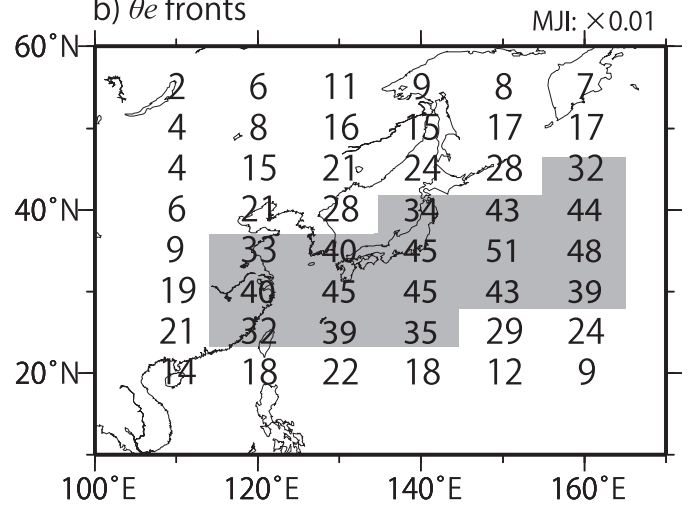

Fig. 2. Distribution maps of MJIs calculated using the T2009 data set and the data sets of (a) $\theta$ or (b) $\theta e$ fronts. The calculation of MJIs was performed using twice-daily data from April to November for a period of 29 years (19792007). The value in each grid in $5^{\circ}$ longitude by $5^{\circ}$ latitude indicates $M J I$ (unit: $\times 0.01$ ). Each value is calculated in $10^{\circ}$ width of latitude along every $5^{\circ}$ longitude. The shaded grids indicate high values, more than 0.300 .

2. However, the temporal dispersion of MJIS is smaller than the spatial dispersion and even the smallest $M J I$, which appears in August when using $\theta e$ fronts, indicates values greater than +0.300 . The other features of the comparison include the MJIs obtained when using $\theta e$ fronts are larger than those obtained when using $\theta$ fronts in the periods from April to June, including the pre-Baiu and the Baiu season. The reason that the $\theta e$ fronts better correspond to the T2009 data set in those seasons as compared to $\theta$ fronts is assumed to be the features of the Baiu front, which is characterized more by humidity than by temperature, especially in the early period of the Baiu season (Kurashima and Hiranuma 1970; Kato 1985; Matsumoto 1988).

On the basis of the spatial and temporal features of
Table 1. The maximum Jaccard Index $(M J I)$ and the thresholds of $d \tau$ and $\operatorname{TFP}(\tau)$ when using (a) $\theta$ and (b) $\theta e$ fronts, which were calculated each month from April to November for 29 years (1979-2007). The bottom row of the table shows the same except for the period from April to November. The units of $d \theta$ and $d \theta e$, and $\operatorname{TFP}(\theta) \operatorname{TFP}(\theta e)$ are $\mathrm{K}(100 \mathrm{~km})^{-1}$ and $\mathrm{K}(100 \mathrm{~km})^{-2}$, respectively.

\begin{tabular}{l|ccc}
\hline a) $\theta$ fronts & MJI & TFP $(\theta)$ & $d \theta$ \\
\hline April & 0.397 & 0.13 & 0.37 \\
May & 0.414 & 0.08 & 0.27 \\
June & 0.520 & 0.06 & 0.14 \\
July & 0.474 & 0.06 & 0.20 \\
August & 0.349 & 0.13 & 0.18 \\
September & 0.447 & 0.13 & 0.17 \\
October & 0.421 & 0.14 & 0.17 \\
November & 0.386 & 0.19 & 0.25 \\
\hline Apr.-Nov. & 0.414 & 0.11 & 0.17 \\
\hline \hline b) $\theta e$ fronts & MJI & TFP $(\theta e)$ & $d \theta e$ \\
\hline April & 0.433 & 0.75 & null \\
May & 0.483 & 0.86 & null \\
June & 0.579 & 0.70 & null \\
July & 0.465 & 0.63 & null \\
August & 0.328 & 0.83 & 0.35 \\
September & 0.427 & 0.81 & null \\
October & 0.411 & 0.80 & 0.39 \\
November & 0.373 & 0.70 & 0.30 \\
\hline Apr.-Nov. & 0.440 & 0.75 & null \\
\hline
\end{tabular}

MJIs in Fig. 2 and Table 1, the region of $120^{\circ}-160^{\circ} \mathrm{E}$, $25^{\circ}-40^{\circ} \mathrm{N}$ and the April-November period became the focus of this work to make one frontal data set. When the $M J I$ and conditions of thermal parameters in that region and period were reviewed, it was found that the MJIS were +0.414 when using $\theta$ fronts and the conditions in $d \theta>0.17 \mathrm{~K}(100 \mathrm{~km})^{-1}$ and $\operatorname{TFP}(\theta)>$ $0.11 \mathrm{~K}(100 \mathrm{~km})^{-2}$, and were +0.440 when using $\theta e$ fronts and the conditions in $\operatorname{TFP}(\theta e)>0.75 \mathrm{~K}(100$ $\mathrm{km})^{-2}$, as can be inferred from the bottom rows of Tables $1 \mathrm{a}$ and $1 \mathrm{~b}$, respectively. Moreover, when the $M J I s$ were calculated by changing the conditions of the four parameters; $\theta, \theta e, \operatorname{TFP}(\theta)$, and $\operatorname{TFP}(\theta e)$, an MJI of +0.453 was obtained when using the conditions in $d \theta$ $>0.04 \mathrm{~K}(100 \mathrm{~km})^{-1}, \operatorname{TFP}(\theta)>0.05 \mathrm{~K}(100 \mathrm{~km})^{-2}$ and $T F P(\theta e)>0.69 \mathrm{~K}(100 \mathrm{~km})^{-2}$ with no conditions for $d \theta e$, which indicated higher values than those when using $\theta$ or $\theta e$ fronts alone. Therefore, the frontal data set calculated on the basis of these conditions was chosen for this work. 


\section{Characteristics of frontal data set}

To demonstrate the seasonal march of the frontal zone around Japan using the frontal data set made by intersection of the $\theta$ and $\theta e$ fronts (PETF) (conditions: $d \theta>0.04 \mathrm{~K}(100 \mathrm{~km})^{-1}, \operatorname{TFP}(\theta)>0.05 \mathrm{~K}(100 \mathrm{~km})^{-2}$, and $\left.\operatorname{TFP}(\theta e)>0.69 \mathrm{~K}(100 \mathrm{~km})^{-2}\right)$, the time-latitude sections of the 62-year (1948-2009) average frontal frequencies along $130^{\circ} \mathrm{E}$ and $140^{\circ} \mathrm{E}$ are shown in Figs. $3 \mathrm{a}$ and $3 \mathrm{~b}$. Figs. $3 \mathrm{c}-\mathrm{h}$ also exhibit the seasonal march, in these cases for the data set of $\theta$ fronts $(\mathrm{PTF})$ with conditions $d \theta>0.17 \mathrm{~K}(100 \mathrm{~km})^{-1}$ and $\operatorname{TFP}(\theta)>0.11$ $\mathrm{K}(100 \mathrm{~km})^{-2}$ (Figs. $3 \mathrm{c}$ and $\left.3 \mathrm{~d}\right)$; for the data set of $\theta e$ fronts (ETF) with conditions $\operatorname{TFP}(\theta e)>0.75 \mathrm{~K}(100$ $\mathrm{km})^{-2}$ (Figs. 3e and 3f); and for the T2009 data set (Figs. $3 \mathrm{~g}$ and $3 \mathrm{~h}$ ). These conditions of the PTF and ETF were derived from the values in the bottom rows of Tables $1 \mathrm{a}$ and $1 \mathrm{~b}$. Although Figs. $3 \mathrm{~g}$ and $3 \mathrm{~h}$ show the 29-year (1979-2007) average frontal frequencies from April to November owing to the limited periods of the data source, all of Figs. $3 \mathrm{a}-\mathrm{h}$ similarly indicate the average seasonal march of the frontal zone. Frequencies are expressed as the mean rate $(\%)$ of fronts by $3^{\circ}$ latitude width and by each weather map.

In the seasonal march of frontal zones using the T2009 data set (Figs. $3 \mathrm{~g}$ and 3h), the frontal zone is seen to shift northward around $20^{\circ}-45^{\circ} \mathrm{N}$ from April to August and southward from August to November. High frontal frequencies (more than $25 \%$ ) along $140^{\circ} \mathrm{E}$ are found from June to July and from September to October, which correspond to the Baiu fronts and the Akisame fronts in Japan, respectively (Fig. 3h). Frontal frequencies along $130^{\circ} \mathrm{E}$ (Fig. $3 \mathrm{~g}$ ) are as high as those along $140^{\circ} \mathrm{E}$ in the Baiu season but low in the Akisame season; this behavior corresponds to the characteristics shown by Yoshino (1965) and Takahashi (2003), respectively.

In the PTF and ETF calculated for this work (Figs. $3 \mathrm{c}-\mathrm{f}$ ), similar shifts of the frontal zone and two maximum values of the frontal frequencies can be identified. However, there are some differences in frequencies with the T2009 data set. The PTF (Figs. 3c and $3 \mathrm{~d}$ ) indicates there are three or four frontal zones from November to May, which are not found in the T2009 data set for the same period (Figs. $3 \mathrm{~g}$ and $3 \mathrm{~h}$ ). The frontal frequencies of the PTF are lower during the late period of the Baiu season (early to mid-July) and higher during the late period of the Akisame season (October or later) along $130^{\circ} \mathrm{E}$ than those of the T2009 data set, respectively. On the other hand, the ETF (Figs. 3e and 3f) shows more similar characteristics to the T2009 data set, i.e., one frontal zone is seen around
Japan. This is the important reason for the higher $M J I$ of the ETF than that of the PTF, as shown in Section 2.2. In spite of indicating the higher $M J I$ of the ETF, there are two periods when the ETF has no similarity to results from the T2009 data set, in contrast to the results from its relationship with the PTF. The frontal frequencies of the ETF are much higher during the late period of the Akisame season (in October) along $130^{\circ} \mathrm{E}$ and much lower during the late period of the Baiu season (early to mid-July) along $140^{\circ} \mathrm{E}$ than those of the PTF and the T2009 data set. Moreover, a shift of the frontal zone around early October from $35^{\circ} \mathrm{N}$ to $30^{\circ} \mathrm{N}$ along $140^{\circ} \mathrm{E}$ is also found; however, this occurs neither in the PTF nor in the T2009 data set.

The Baiu front in the west of $130^{\circ} \mathrm{E}$ and the Akisame front around East Japan $\left(140^{\circ} \mathrm{E}\right)$ are especially characterized by the moisture field and thermal field, respectively (e.g., Kurashima and Hiranuma 1970; Kato 1985; Matsumoto 1988). The characteristics of Figs. $3 \mathrm{c}-\mathrm{h}$ indicate that the ETF and the PTF, which are characterized by the moisture field and thermal field, respectively, can well express the Baiu fronts along $130^{\circ} \mathrm{E}$ and the Akisame fronts along $140^{\circ} \mathrm{E}$. On the contrary, in addition to the difference in numbers of frontal zone of the PTF, the decrease in frequencies during the late period of the Baiu season and the shift of the frontal zone from $35^{\circ} \mathrm{N}$ to $30^{\circ} \mathrm{N}$ around early October along $140^{\circ} \mathrm{E}$ in the ETF were not found in the T2009 data set. These characteristics are considered to be caused by large-scale changes because when these changes occur in late July and early October, they have been reported to correspond to the periods of the turn of the stage; the starts of Stage III in the Baiu season (Yoshino 1965) and of the late autumn rainy season (Takahashi 2003), respectively. These interesting characteristics should be examined in detail in the future work.

The time-latitude sections of the frontal frequencies of the PETF (Figs. 3a and 3b) bear a greater similarity to those of the T2009 data set than those of the PTF and ETF; that is, only one frontal zone, as seen in the T2009 data set, is observed around Japan and the frontal frequencies in October at $130^{\circ} \mathrm{E}$ and from April to May at $140^{\circ} \mathrm{E}$ are closer to those of the T2009 data set than of the ETF. The similarities between the frontal data set and the T2009 data set are also observed in $M J I$, as shown in Section 2.2. However, some differences in frequencies with the T2009 data set remain. Frequencies lower than those of the T2009 data set were observed from late June to mid-July, while higher frequencies were observed along $140^{\circ} \mathrm{E}$ in late August and along $130^{\circ} \mathrm{E}$ from late September to 
a) $130^{\circ} \mathrm{E}$, intersection of $\theta$ and $\theta e$ fronts

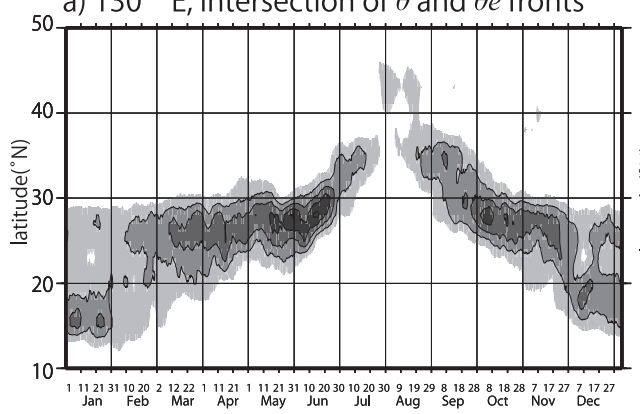

c) $130^{\circ} \mathrm{E}, \theta$ fronts

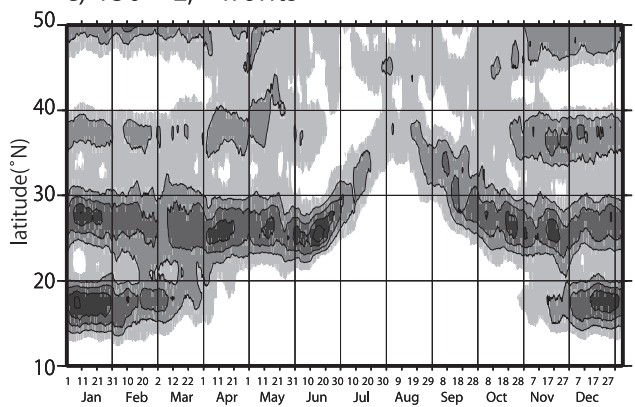

e) $130^{\circ}$ E, $\theta e$ fronts

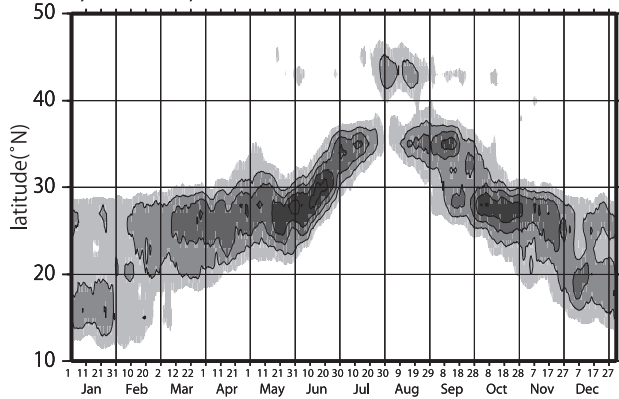

g) $130^{\circ} \mathrm{E}$, fronts on weather maps (T2009)

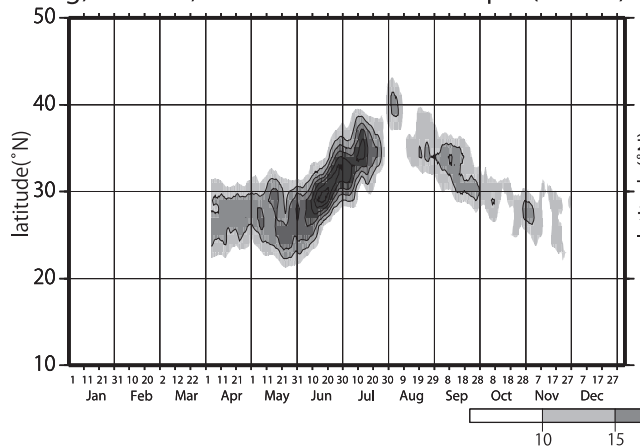

b) $140^{\circ} \mathrm{E}$, intersection of $\theta$ and $\theta e$ fronts

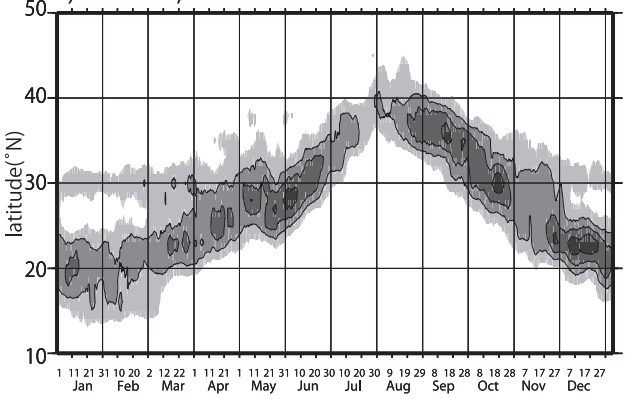

d) $140^{\circ} \mathrm{E}, \theta$ fronts

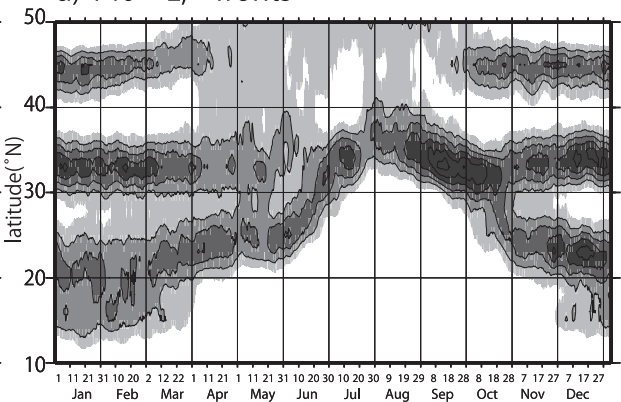

f) $140^{\circ} \mathrm{E}, \theta e$ fronts

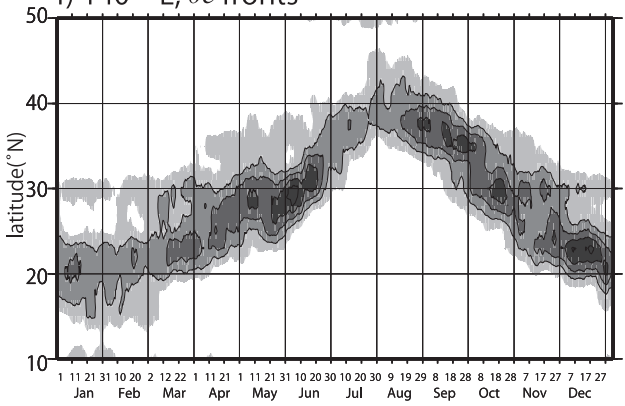

h) $140^{\circ} \mathrm{E}$, fronts on weather maps (T2009)

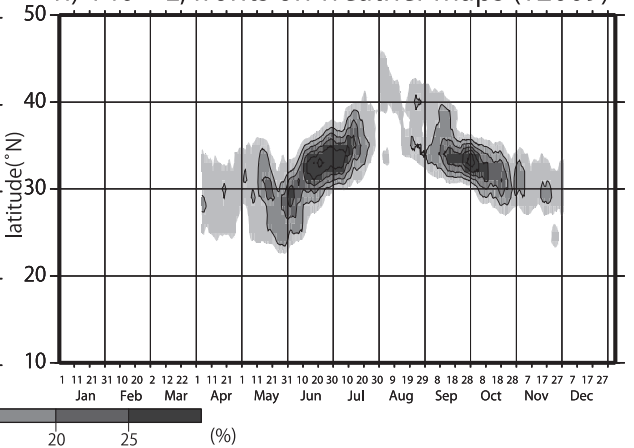

Fig. 3. Time-latitude sections of frontal frequencies along $130^{\circ} \mathrm{E}((\mathrm{a}),(\mathrm{c}),(\mathrm{e})$, and $(\mathrm{g}))$ and $140^{\circ} \mathrm{E}((\mathrm{b}),(\mathrm{d}),(\mathrm{f})$, and (h)). The figures of (a) and (b), (c) and (d), (e) and (f), and (g) and (h) show the intersection of $\theta$ and $\theta e$ fronts (PETF), $\theta$ fronts (PTF), $\theta e$ fronts (ETF), and the T2009 data, respectively. The temporal resolutions and the data periods of (a)-(f) are six-hourly and 62-year (1948-2009), and those of (g) and (h) are 12-hourly and 29-year (1979-2007) from April to November. The contour interval is $5 \%$ above $10 \%$. 
a) fronts on weather maps (T2009)

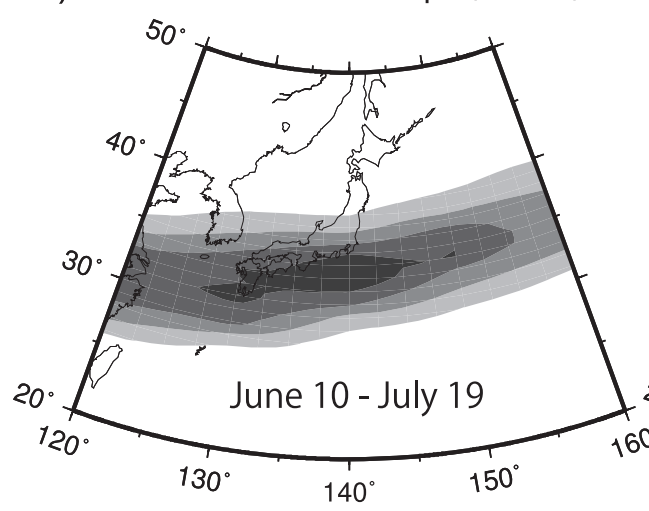

C) fronts on weather maps (T2009)

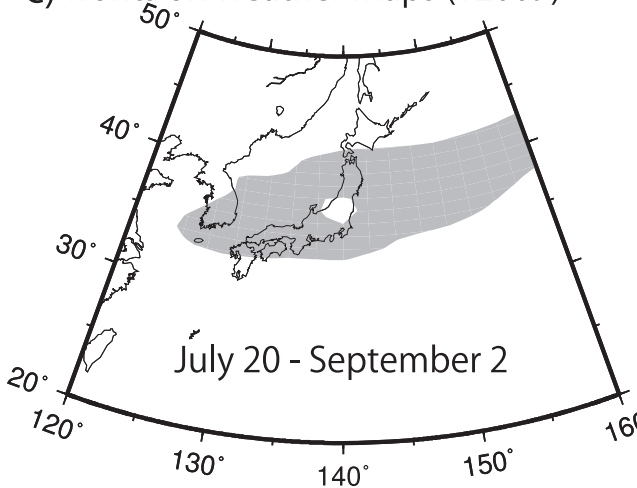

e) fronts on weather maps (T2009)

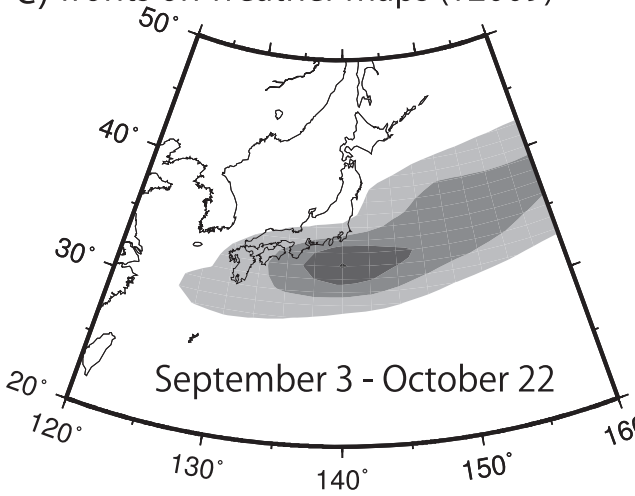

b) intersection of $\theta$ and $\theta e$ fronts

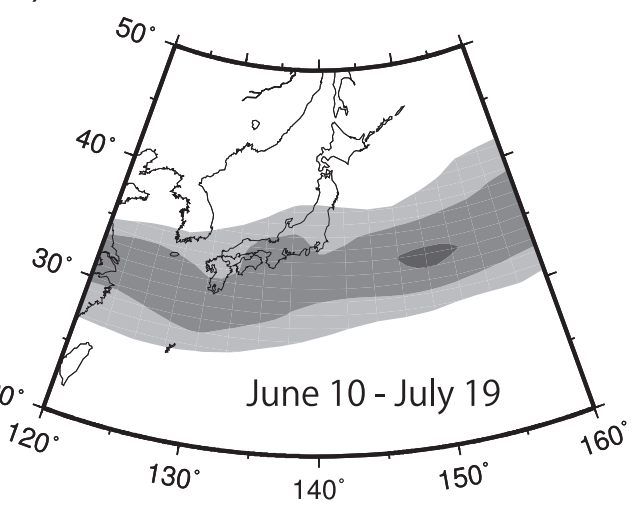

d) intersection of $\theta$ and $\theta e$ fronts

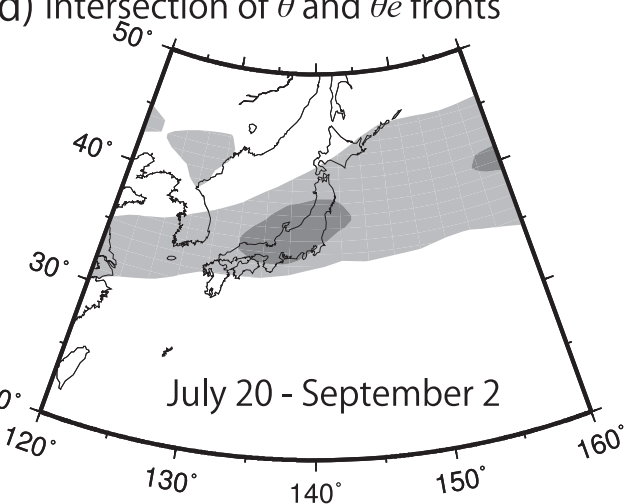

f) intersection of $\theta$ and $\theta e$ fronts

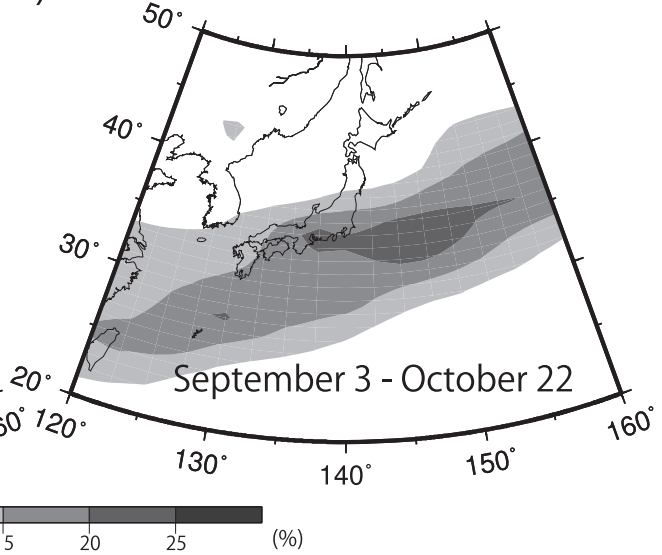

Fig. 4. Distribution maps of the average frontal frequencies in the case of using the T2009 data set ((a), (c), and (e)) and the PETF ((b), (d), and (f)). The periods of (a) and (b), (c) and (d), and (e) and (f) refer to the Baiu (June 10-July 19), mid- and late-summer (July 20-September 2), and Akisame (September 3-October 22) seasons, respectively.

mid-November. Figure 4 presents the distribution maps of the average frontal frequencies for the periods of the Baiu (June 10-July 19), mid- and late-summer (July 20-September 2), and Akisame (September 3October 22) seasons using the T2009 data set (Figs. 4a, 4c, and 4e) and PETF (Figs. 4b, 4d, and 4f). The difference between the T2009 data set and PETF became clear in each season, and the frontal frequencies using the PETF were lower than those of the T2009 data set in the Baiu season, but higher 
around eastern Japan in the mid- and late-summer and around western Japan in the Akisame season. In particular, the high frontal frequencies west of $130^{\circ} \mathrm{E}$ calculated for the Akisame season are not usually observed in the frontal analysis of the daily weather maps.

Given the above data, the characteristics of the PTF and ETF in each period and region were revealed. Furthermore, it was verified that the PETF was the most suitable frontal data set to use for the vicinity of Japan, which endorses the suggestion by Hewson (1998); the intersection of $\theta$ and $\theta w(\theta e)$ fronts is more compatible to the analyzed fronts on the weather maps than $\theta$ or $\theta w(\theta e)$ fronts alone. In particular, the seasonal marches of the frontal zone, which were drawn by the axis of the frontal frequencies, were similar in both frontal data sets of T2009 and PETF. However, note that some differences remain; the frontal frequencies of the PETF were lower during the late period of the Baiu season and higher around East Japan in the mid and late summer and around West Japan in the Akisame season than those of the T2009 data set. In other words, the examination of the reason for differences between the T2009 data set and PETF, and the further improvement of the objective frontal data set are subjects for future works.

\section{Relationship of interannual variation between weather and frontal zone in mid-summer}

To clarify the effects of the frontal zone on the climate of Japan, the interannual relationship between the distribution of the frontal frequencies and the clearsky ratio (\%) during mid-summer (July 20-August 18) was examined as an example. The clear-sky ratio is defined as the percentage of the day with precipitation less than $1 \mathrm{~mm}$ day $^{-1}$ and daily mean cloud cover less than $85 \%$. The data are acquired from 150 observation stations of the JMA as shown in Figure 6, and each station has less than $16 \%$ missing data during midsummer for 49 years from 1961 to 2009. The 150 stations were first classified on the basis of the result of cluster analysis for the interannual clear-sky ratios in each station. Cluster analysis is often utilized to perform climatic classification for meteorological elements (e.g., Kato 1983, Takahashi 2001). The distance matrix of this analysis comprised the values obtained by multiplying -1 by correlation coefficients between the interannual clear-sky ratios of each station. A clustering of stations was performed using the distance matrix by Ward's linkage method. Cluster consolidation was stopped just before the remote regions were consolidated, and divided the Japanese

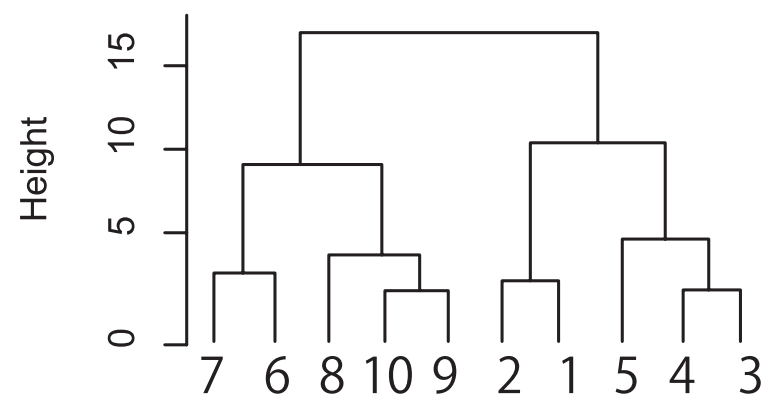

Fig. 5. A dendrogram of the cluster analysis for the interannual clear-sky ratios of the 150 stations during midsummer of 49 years from 1961 to 2009 . The numbers indicate clusters $1-10$, respectively.

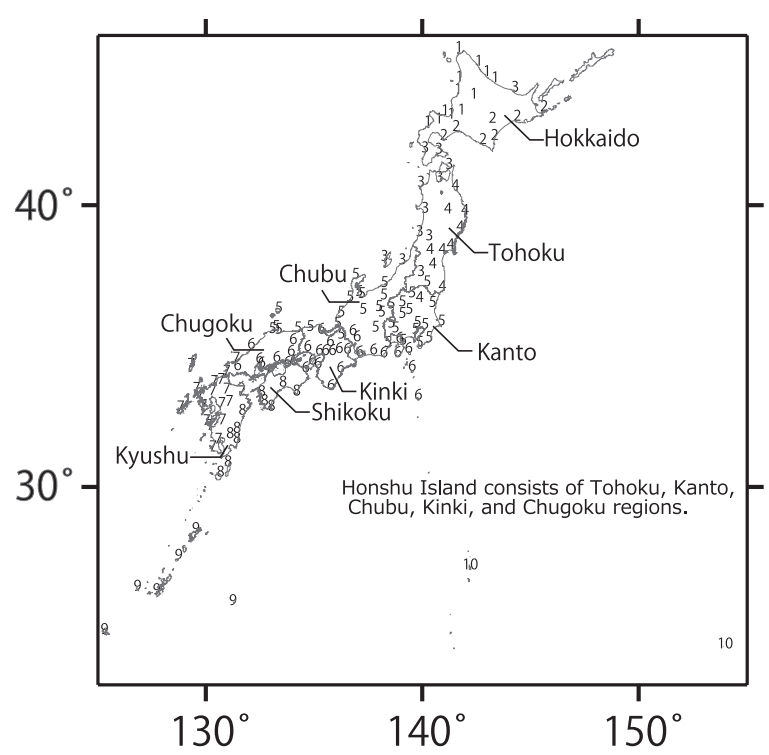

Fig. 6. A Distribution map of the cluster analysis for the interannual clear-sky ratios of the 150 stations during midsummer of 49 years from 1961 to 2009. The numbers indicate clusters $1-10$, respectively.

Archipelago into 10 regions (clusters 1-10). Figures 5 and 6 show the results of the cluster analysis and the dendrogram plus map of the regional divisions, respectively. As shown in Figs. 5 and 6, cluster consolidations were stopped just before conjunction between the clusters 9 and 10, the regions of which are physically apart from each other.

To reveal the relationships between the regionalaveraged clear-sky ratio and the frontal frequencies, a correlation analysis was performed between these two quantities during mid-summer of 49 years from 1961 

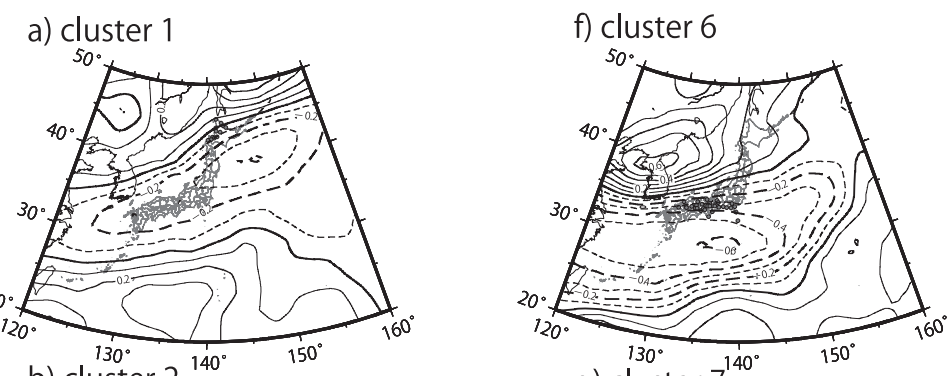

b) cluster $2^{140^{\circ}}$

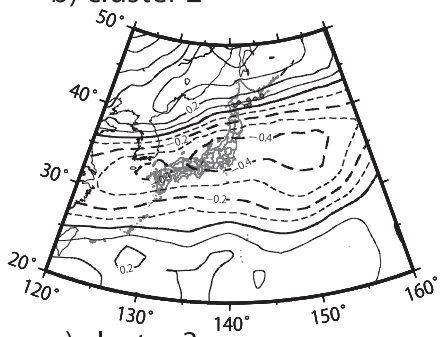

g) cluster $7^{140^{\circ}}$

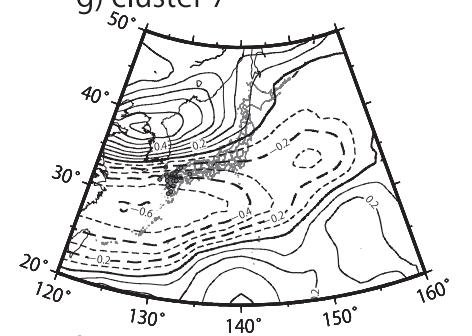

c) cluster 3

h) cluster 8
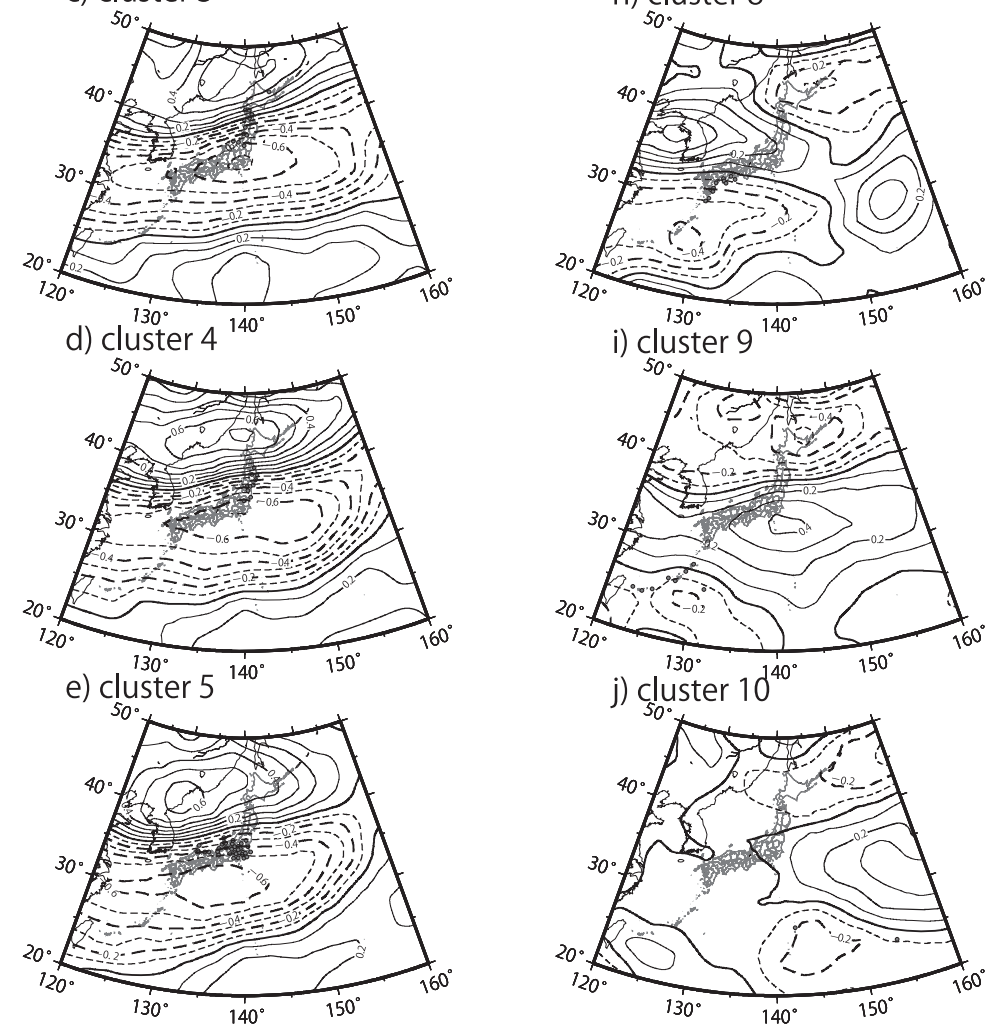

Fig. 7. Distribution maps of the correlation coefficients between the cluster-averaged clear-sky ratio and the frontal frequencies during mid-summer of 49 years from 1961 to 2009 . The captions of (a)-(j) correspond to the clusters 1-10, respectively. The contour interval is 0.1 . The value of positive, negative, and 0 are drawn by the solid, dashed, and thick line, respectively. 
to 2009. Figure 7 shows the correlation map in each cluster. Contour intervals are 0.1 , and the negative values indicate that the numbers of the frontal frequencies are high (low) when the clear-sky ratio is low (high) in mid-summer. Statistically, the significance at the $99 \%$ level corresponds to the correlation coefficients \pm 0.366 .

Figure 7 show that the minimum values of the correlation coefficients are found in the $200-400 \mathrm{~km}$ south of each region with significance for most of the clusters 1-10. These positional relationships are understandable because cloud areas near fronts often spread more on the north side of fronts on a daily basis, particularly in the case of a stationary or a warm front. The minimum values in most part of Honshu (clusters 3-7; Figs. 7c-g) are much lower than -0.6 , which indicates the clear-sky ratios in Honshu are strongly influenced by the frontal zone locating in the south of each region. On the other hand, the minimum values locating in the south of Hokkaido (clusters 1 and 2; Figs. 7a and 7b) and South Japan (clusters 8-10; Figs. $7 \mathrm{~h}-\mathrm{j}$ ) are not as low as -0.6 . The correlation coefficients with these minimum values around Hokkaido (clusters 1 and 2; Figs. 7a and 7b) suggest that the influences of other factors on the clear-sky ratio in this region are comparable to the influence of the frontal zone (e.g., the occurrence of the Okhotsk high, depressions without fronts in the high latitudes, and frequent sea fog and low level cloud around the Pacific coast of Hokkaido in summer). Of particular importance is the occurrence and development of the Okhotsk high and its influence on the summer climate variations of Hokkaido, as discussed in Nakamura and Fukamachi (2004) and Tachibana et al. (2004). Regarding South Japan (clusters 8-10; Figs. 7h-j), spatial characteristics other than the negative values near the south of each region were observed that include negative coefficients near Hokkaido at approximately $45^{\circ} \mathrm{N}, 142.5^{\circ} \mathrm{E}$ and positive coefficients covering the Kanto region. Considering the average distribution of the frontal frequencies in mid- and latesummer (see Fig. 4d), these characteristics suggest northward shifts of the frontal zone and the zonal ridge of the Pacific high when clear-sky ratios are low. In these cases, positive and negative coefficients around the northwestern Pacific are also considered to correspond to the areas where the Pacific high extends and withdraws, respectively. Therefore, because each region of clusters $8-10$ is located at either edge of the west, southwest, or south of the Pacific high, (where the water vapor transport from the tropics to midlatitudes and associated convective activities are often seen), it is understandable that there is a decrease in the clear-sky ratio in each region.

Thus, the location of the frontal zone affecting the interannual variations in the clear-sky ratio and the degree of these influences were observed in each region by using the frontal data set. These characteristics can help to better understand the regional climate from the atmospheric grid data, e.g., reanalysis data of past conditions and output data on a simulation model of future conditions.

\section{Seasonal march of frontal zone in El Niño/La Niña events}

As an additional check, the seasonal march of the frontal zone around Japan when El Niño/La Niña events occur was verified using the frontal data set created in this work. It is well known that El Niño/La Niña events tend to begin in spring and peak during the boreal winter, causing effects on the climate of Japan in various manners, e.g., leading to cool/hot summer and warm/cold winter, respectively (e.g., Miyazaki 1989, JMA 2005). Moreover, a delayed impact on the East-Asian summer atmosphere circulation in the year following El Niño events has been reported (Wang et al. 2001, Xie et al. 2009). Similarly, JMA (2005) has also reported a delayed end of the Baiu season in Japan during El Niño events. Therefore, this check focused on the periods from spring (March), when El Niño/La Niña events normally begin to grow, to summer (August) in the following year.

The El Niño/La Niña events are defined by the JMA as the periods when the five-month running average of the Niño-3 $\left(5^{\circ} \mathrm{S}-5^{\circ} \mathrm{N}, 150^{\circ}-90^{\circ} \mathrm{W}\right)$ sea surface temperature (SST) index is more/less than $+0.5^{\circ} \mathrm{C} /$ $-0.5^{\circ} \mathrm{C}$ and continues to be so for six months, respectively. Because the length of the periods in each El Niño/La Niña event is different, in order to extract the typical El Niño/La Niña events, the El Niño/La Niña period was defined as the "year," and included the periods from July to January in the next year, thereby satisfying the definition of the JMA. The El Niño/La Niña years defined thus are listed in Table 2. Figure 8 shows the time-latitude section of the frontal frequencies (gray scale) and their anomalies from climatology (1948-2009) (contour) along $130^{\circ} \mathrm{E}$ and $140^{\circ} \mathrm{E}$ averaged in the El Niño or La Niña events. Figure 9 also shows the distributions of the frontal frequencies and their anomalies during the definite periods. Note that the significance level of the anomalies discussed below is not so high, generally $70 \%$ or more.

The characteristics of the seasonal march of the 
Table 2. A list of the El Niño and the La Niña years defined in this work.

\begin{tabular}{|c|c|}
\hline El Niño years (13 years) & La Niña years (14 years) \\
\hline 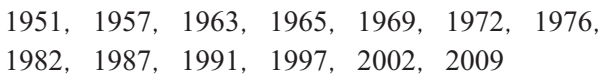 & $\begin{array}{lllllll}1949, & 1954, & 1955, & 1964, & 1970, & 1971, & 1973, \\
1975, & 1984, & 1988, & 1995, & 1998, & 1999, & 2007\end{array}$ \\
\hline
\end{tabular}
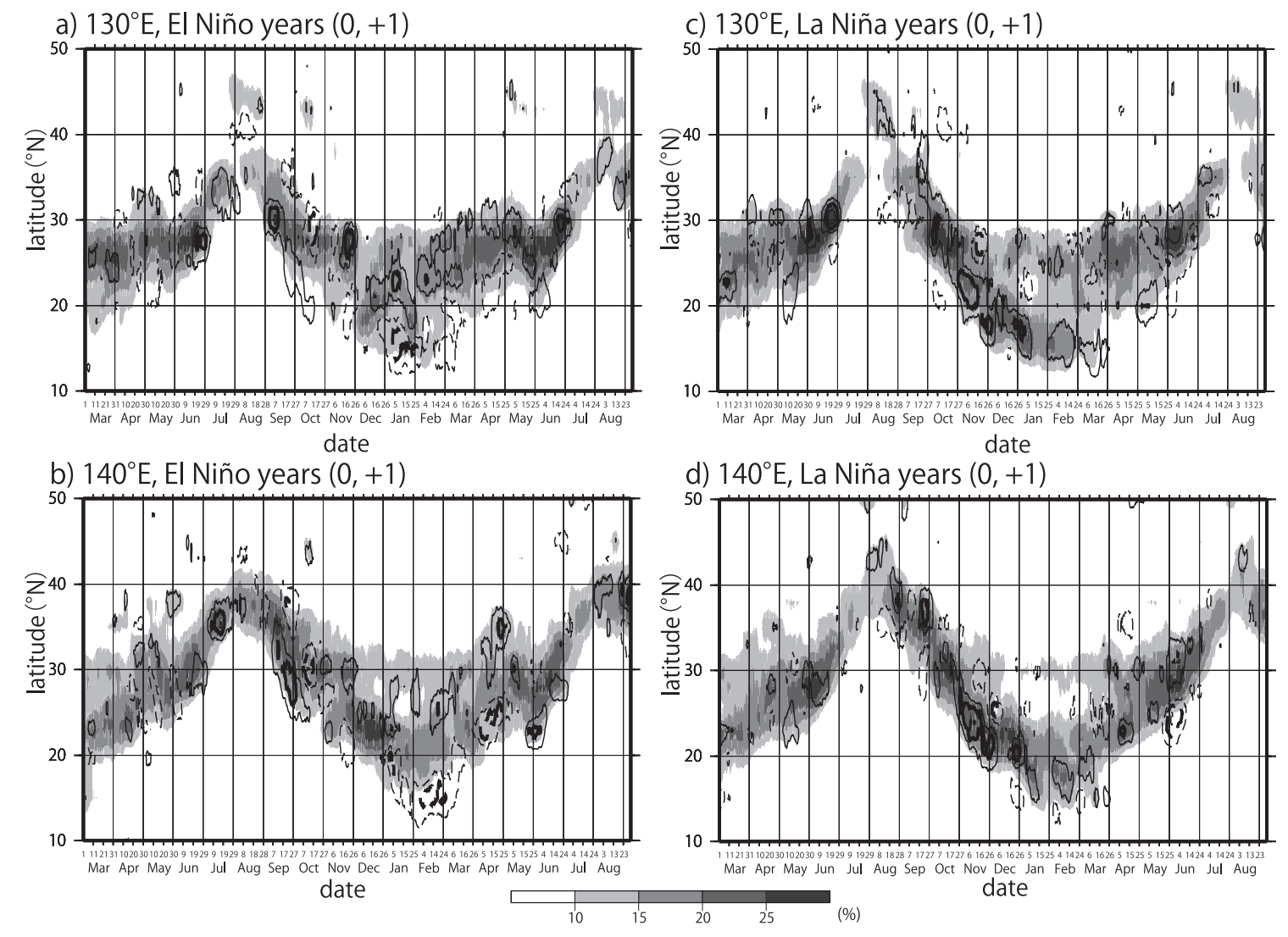

Fig. 8. Time-latitude sections of frontal frequencies and their anomalies along $130^{\circ} \mathrm{E}$ and $140^{\circ} \mathrm{E}$ in (a)-(b) the El Niño years and (c)-(d) La Niña years. The contour line indicates the anomaly, and its interval is 3\% (the contour of $0 \%$ is not shown and the thick line indicates $6 \%$ or $-6 \%$ ). The solid and dashed lines indicate positive and negative values, respectively.

frontal frequencies in the El Niño events (Figs. 8a and $8 \mathrm{~b})$ vary depending on the periods. In July, in the latter part of and after the Baiu season, the frontal frequencies are higher around the south coast of Japan (Figs. 8a, 8b, and 9a). This characteristic exhibits the well-known halt of frontal zone migration and delayed end of the Baiu season in the El Niño years (JMA 2005). During the Akisame season from early September to mid-October, the frontal frequencies are lower and higher than those in climatology in the north and south side of the frontal zone (the axis of the frontal frequencies), respectively, which indicates the southward shifts of the frontal zone in that season or rapid seasonal march from summer to autumn (Figs. $8 \mathrm{a}, 8 \mathrm{~b}$, and $9 \mathrm{~b})$. In contrast, around the winter from mid-November to April in the next year, this behavior reverses and the frontal frequencies are higher and lower in the north and south side of the frontal zone, respectively, indicating the northward shifts of the frontal zone. During the summer following El Niño events, there are two periods when higher frontal frequencies are found along the frontal zone from 

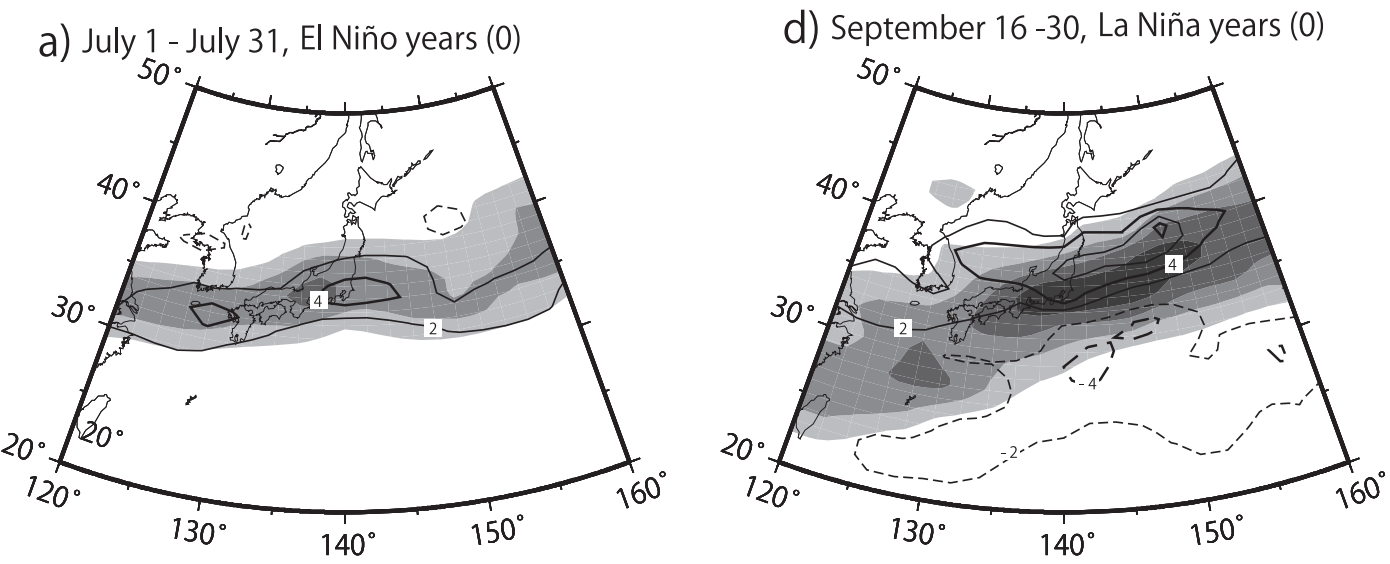

b) September 16 - October 15, El Niño years (0)

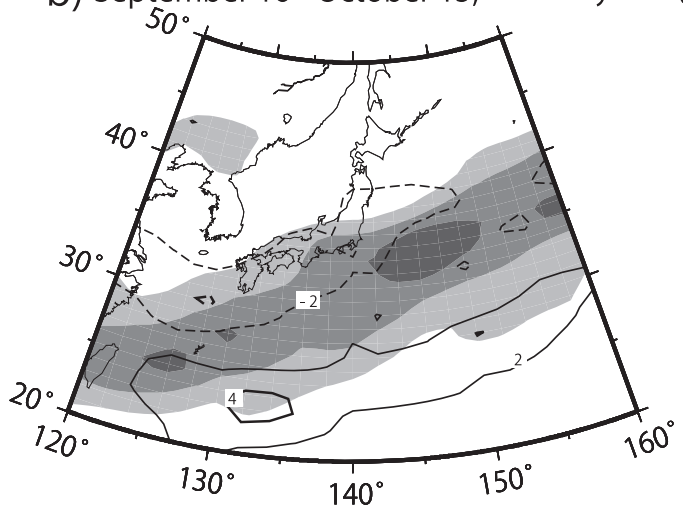

C) July 26 - August 10, El Niño years $(+1)$

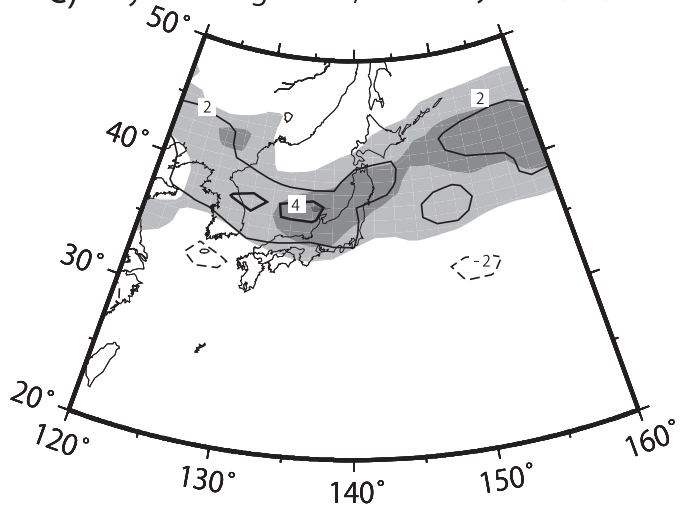

e) November 11 - 30, La Niña years (0)
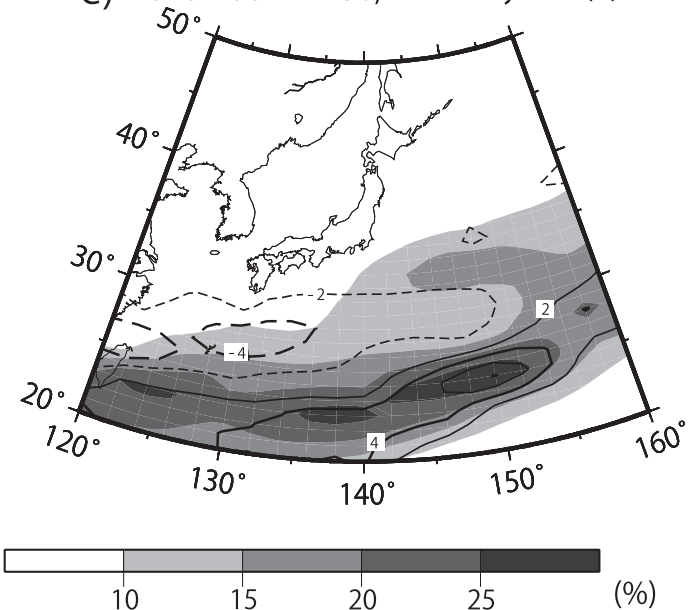

Fig. 9. Distribution maps of the averaged frontal frequencies and their anomalies for the periods of (a) July $1-$ July 31 in the El Niño years, (b) September 16-October 15 in the El Niño years, (c) July 26-August 10 in the next years of the El Niño years, (d) September 16-30 in the La Niña years, and (e) November 11-30 in the La Niña years. The contour line indicates anomaly and its interval is $2 \%$ (the contour of $0 \%$ is not shown). The solid and dashed lines indicate positive and negative, respectively.

$130^{\circ} \mathrm{E}$ to $140^{\circ} \mathrm{E}$. Higher frontal frequencies are found on the southern side or around the frontal zone in June (from late May), and around the frontal zone from late July to August (Figs. 8a and 8b). The characteristic of the latter period is conspicuous when focusing on distribution maps of frontal frequencies averaged from July 26 to August 10 (Fig. 9c).

Next, the seasonal march of the frontal frequencies 
during La Niña events was determined (Figs. 8c and $8 \mathrm{~d})$. In the Baiu season and the mid-summer in the La Niña years, there are no large anomalies found around Japan, except for the short period in late June along $130^{\circ} \mathrm{E}$ - though positive anomalies are seen in those seasons when El Niño events occur (Figs. 8a and 8b). On the other hand, anomalies of more than 3\% appear around the north side of the frontal zone from August to October, indicating the northward shifts of the frontal zone compared with climatology. The axis of these positive anomalies moves from the northern side to the southern side of the frontal zone around early November. The high frequencies and large positive anomalies thereafter are maintained at the lower latitude around the winter from November to March. These anomalies have an opposite sense to the position of the frontal zone between before and after early November as seen in Figs. 9d and 9e.

These characteristics of the frontal zone are almost in agreement with the observations made in previous works. JMA (2005) summarized the former researches about El Niño and La Niña events and showed the atmospheric circulations around Japan in these events, e.g., the weak western Pacific high accompanied with the southward shifts of the subtropical jet, the storm track, and the frontal zone during the summer in the El Niño events, the weakness of the zonal pressure gradient around Japan associated with the anomalous Philippine Sea anticyclone (Wang and Zhang 2002) and the Pacific/North American teleconnection pattern (PNA) (Horel and Wallace, 1981) during the winter in the El Niño events, and their opposite features in the La Niña events. Because the frontal zone around Japan usually locates in the northed side of the subtropical high, the characteristics of the circulation patterns reported by previous works are consistent with that the frontal zone shifts from lower/higher to higher/lower latitude than normal bordering on early- or midNovember during El Niño/La Niña events, respectively, and with that the high frontal frequencies around the south coast of Japan are seen from the later part of the Baiu season to the early summer in the El Niño years, as observed in this work. Furthermore, considering that the southward (northward) shifts of the frontal zone bring cooler or colder (warmer or hotter) air masses over a large part of Japan, it is understandable that the well-known cool/hot summer and warm/cold winter during El Niño/La Niña years, respectively, in Japan correspond to the behavior of the frontal zone, as previously indicated. The high frontal frequencies around Japan in the summer following the El Niño events (e.g., Fig. 9c) are also considered to correspond to atmospheric conditions suitable for the formation of the fronts in East Asia as shown by Wang et al. (2001), i.e., the western Pacific high extends abnormally westward, and an anomalous blocking anticyclone tends to occur in northeast Asia. Xie et al. (2009) also indicate that these atmospheric conditions in the summer following the El Niño events have corresponded to favorable conditions for rainfall occurrence around Japan and that these conditions are ascribable to the SST increase and its persistence through the summer over the tropical Indian Ocean.

In conclusion, various mean characteristics of the climate of Japan during El Niño/La Niña events, which have been indicated in previous reports, can be verified from the perspective of the seasonal march of the frontal zone, which has not been clarified so far. Note that the frontal frequency anomalies associated with El Niño/La Niña events in this work are not statistically highly significant. One of the reasons is considered to be the characteristics of the frontal data- even if there is a tendency of a southward shift of the frontal zone during an event, the statistical relationship improves only in one of the grids located in the south of the frontal zone and simultaneously worsens in other grids along the same meridian line. Moreover, the climate of Japan is controlled not only by tropical circulation such as El Niño/La Niña events but also by the atmospheric circulation of the middle and high latitudes, such as the Silk Road pattern in summer shown by Enomoto et al. (2003) and Enomoto (2005) and the Arctic Oscillation in winter summarized by JMA (2005). Therefore, it is necessary to examine in detail the factors involved in the interannual variations in the frontal zone around Japan from the perspective of the atmospheric circulation in the middle and high latitudes as well as the tropical circulation.

\section{Summary}

A long-term (1948-2009) frontal data set was created by the objective method using NCEP-NCAR reanalysis data, and the average seasonal behaviors of the frontal zone around Japan, their influence on the weather in mid-summer, and the seasonal march of the frontal zone when El Niño/La Niña events occur were examined using this frontal data set. The main results are summarized as follows:

1) 3,200,000 types of frontal data sets were created by changing the thresholds of four parameters, i.e., a gradient and a thermal front parameter (TFP) of a potential temperature and an equivalent potential temperature $(d \theta, d \theta e$, $\operatorname{TFP}(\theta)$, and $T F P(\theta e))$ at $850 \mathrm{hPa}$, which 
determine the existence of a front in each grid. Each data set was then compared with the frontal data set around Japan, which was compiled by counting the number of fronts on surface weather maps published by the JMA (the T2009 data set). It was revealed that the frontal data set generated under the conditions of $d \theta>0.04 \mathrm{~K}(100 \mathrm{~km})^{-1}$, $\operatorname{TFP}(\theta)>0.05 \mathrm{~K}(100 \mathrm{~km})^{-2}$, and $\operatorname{TFP}(\theta e)>0.69$ $\mathrm{K}(100 \mathrm{~km})^{-2}$ showed the strongest correlation to that of the T2009 data set.

2) The long-term frontal data set created in this work retained some differences in frequency with that of T2009-for example, the frontal frequencies were lower in the Baiu season and higher in mid-summer and the early Akisame season than those of the T2009 data set. However, the seasonal march of the frontal zone, which was drawn as the axis of the frontal frequencies, was consistent with that of the T2009 data set.

3) The relationship for the interannual variation of the mid-summer (July 20-August 18) between the clear-sky ratio and the frontal zone was examined in each classified region by the correlation analysis. These results indicate that the clear-sky ratio in each region, particularly Honshu, is closely associated with variations in the frontal frequencies $200-400 \mathrm{~km}$ south of each region. These relationships are not very strong in Hokkaido and South Japan, probably because of additional factors; for example, the occurrence of the Okhotsk high and the water vapor transport from the tropics as for Hokkaido and South Japan, respectively, thereby influencing the weather in each region.

4) The seasonal marches of the frontal zone around Japan when El Niño/La Niña events occur are exhibited by the frontal data set. The frontal zone shifts from lower/higher to higher/lower latitude than normal bordering on early- or midNovember during El Niño/La Niña events, respectively. The characteristics of the high frequencies around the south coast of Japan in the period from the later part of the Baiu season to the early summer in the El Niño years and of the high frontal frequencies around Japan in the summer following the El Niño event are also observed. Thus, various mean characteristics of climate of Japan when El Niño/La Niña events occur can be verified from the perspective of the seasonal march of the frontal zone, which has not been clarified so far.
The methodology of creating the frontal data set proposed in this work has the advantage of simplicity and objectivity. The above results indicate that the frontal data set created in this way retains the potential to understand the detailed relationships between the regional climate around Japan and the large-scale atmospheric conditions. Further improvement of creating the frontal data, which correlates to the weather map's fronts, by changing the types of the thermal parameter, the spatial resolutions, and the products of the gridded data, and the research of the various climatic variations using frontal data set are the subjects for future works.

\section{Acknowledgments}

The author would like to thank Dr. Shin Miyazaki, Mr. Koji Ishihara, Dr. Sachie Kanada, and Dr. Tomohiko Tomita for their valuable comments. The author also would like to thank the editor and two anonymous reviewers for their helpful comments. This research was financially supported from the Japan Society for the Promotion of Science, Grant-in-Aid for Young Scientists (B) (No. 22700856).

\section{References}

Alissow, B. P., 1954: Die Klimate der Erde. Berlin, 277 pp. Bergeron, T., 1930: Richtlinien einer dynamischen Klimatologie. Met. Zs., 47, 246-272.

Bolton, D., 1980: The computation of equivalent potential temperature. Mon. Wea. Rev., 108, 1046-1053.

Enomoto, T., B. Hoskins, and Y. Matsuda, 2003: The formation mechanism of the Bonin high in August. Quart. J. Roy. Meteor. Soc., 129, 157-178.

Enomoto, T., 2005: The formation mechanism of the Ogasawara High in late summer. Tenki, 52, 523-531 (in Japanese).

Hewson, T. D., 1998: Objective fronts. Meteorol. Appl., 5, 3765.

Horel, J.D., and J.M. Wallace, 1981: Planetary-scale atmospheric phenomena associated with the Southern Oscillation. Mon. Wea. Rev., 109, 813-829.

Horn, B. K. P., 1981: Hill-shading and the reflectance map. Proceedings of the IEEE, 69, 14-47.

Japan Meteorological Agency, 1988: On the improvement of the significant weather chart. Weather Serv. Bull, 55, 116.

Japan Meteorological Agency, 2005: Report on Recent Climatic Change in the World 2005, 374 pp (in Japanese).

Kalnay, E., M. Kanamitsu, R. Kistler, W. Collins, D. Deaven, L. Gandin, M. Iredell, S. Saha, G. White, J. Woollen, Y. Zhu, M. Chelliah, W. Ebisuzaki, W. Higgins, J. Janowiak, K. C. Mo, C. Ropelewski, J. Wang, A. Leetmaa, R. Reynolds, R. Jenne, and D. Joseph, 1996: 
The NCEP/NCAR 40-year reanalysis project. Bull. Amer. Meteor. Soc., 77, 437-470.

Kato, H., 1983: Regionality of climate in Hokkaido characterized by sunshine duration and daily mean temperature variations. Geogr. Rev. Japan, 56, 1-16 (in Japanese with English abstract).

Kato, K., 1985: On the abrupt change in the structure of the Baiu front over the China Continent in late May of 1979. J. Meteor. Soc. Japan, 63, 20-36.

Kurashima, A., and R. Hiranuma, 1970: Is the Baiu front the polar front? Tenki, 17, 245-246 (in Japanese).

Matsumoto, J., 1988: Large-scale features associated with the frontal zone over East Asia from late summer to autumn. J. Meteor. Soc. Japan, 66, 565-579.

Miyazaki, Y., 1989: Characteristics of the weather over Japan in El Niño years. Tenki, 36, 489-498 (in Japanese).

Nakamura, H., and T. Fukamachi, 2004: Evolution and dynamics of summertime blocking over the Far East and the associated surface Okhotsk high. Quart. J. Roy. Meteor. Soc., 130, 1213-1233.

Renard, R. J., and L. C. Clarke, 1965: Experiments in numerical objective frontal analysis. Mon. Wea. Rev., 93, 547-556.

Serreze, M. C., A. H. Lynch, and M. P. Clark, 2001: The arctic frontal zone as seen in the NCEP-NCAR reanalysis. $J$. Climate, 14, 1550-1567.

Serreze, M. C., and C. M. Hurst, 2000: Representation of mean Arctic precipitation from NCEP-NCAR and ERA reanalyses. J. Climate, 13, 182-201.

Tachibana, Y., T. Iwamoto, M. Ogi, and Y. Watanabe, 2004: Abnormal meridional temperature gradient and its relation to the Okhotsk high. J. Meteor. Soc. Japan, 82, 1399-1415.

Takahashi, H., 2001: On the contribution of daily rainfall to total rainfall amount during the Baiu season over Japan: geographical structure and year-to-year variability. Geogr. Rev. Japan, 74, 217-232 (in Japanese with
English abstract).

Takahashi, N., 2003: Seasonal transition and year-to-year variations of the autumn rainy season in Japan. Geogr. Rev. Japan, 76, 935-956 (in Japanese with English abstract).

Takahashi, N., 2009: Recent trends in the seasonal evolution in Japan using frontal distribution data. Tenki, 6, 713-726 (in Japanese).

Tomita T., T. Yamaura, and T. Hashimoto, 2011: Interannual variability of the Baiu season near Japan evaluated from the equivalent potential temperature. J. Meteor. Soc. Japan, 89, 517-537.

Wang, Y., B. Wang, and J. Oh., 2001: Impact of the preceding El Niño on the East Asian summer atmosphere circulation. J. Meteor. Soc. Japan, 79, 575-588.

Wang, B., and Q. Zhang, 2002: Pacific-East Asian teleconnection. Part II: How the Philippine Sea anomalous anticyclone is established during El Niño development. J. Climate, 15, 3252-3265.

Yazawa, T., 1989: Kiko Chiiki Ronko: Sono Shicho To Tenkai, Kokon shoin, Tokyo, Japan, 738 pp (in Japanese).

Yoshimura, M., 1967: Annual change in frontal zone in the northern hemisphere. Geogr. Rev. Japan, 40, 393-408 (in Japanese with English abstract).

Yoshimura, M., 1985: Frontal Zone. Dictionary of Climatology and Meteorology. Yoshino, M. M., T. Asai, T. Kawamura, H. Shitara, A. Nitta, and I. Maejima (eds.), Ninomiya shoten, Tokyo, Japan, 287 pp (in Japanese).

Yoshino, M. M., 1965: Frontal zones and precipitation distribution in the rainy season over East Asia. Geogr. Rev. Japan, 38, 14-28 (in Japanese with English abstract).

Xie, S.-P., K. Hu, J. Hafner, H. Tokinaga, Y. Du, G. Huang, and T. Sampe, 2009: Indian Ocean capacitor effect on Indo-Western Pacific climate during the summer of following El Niño. J. Climate, 22, 730-747. 